\title{
Chemical Defences in Soft Corals (Coelenterata: Octocorallia) of the Great Barrier Reef: A Study of Comparative Toxicities
}

\author{
John C. Coll ${ }^{1}$, Stephane La Barre ${ }^{1}$, Paul W. Sammarco², William T. Williams ${ }^{2}$ and \\ Gerald J. Bakus ${ }^{3}$ \\ ${ }^{1}$ Department of Chemistry and Biochemistry, James Cook University of North Queensland, Townsville, Q1d. 481 1, Australia
2 Australian Institute of Marine Science, P.M.B. No. 3, M. S. O., Townsville, Qld. 4810, Australia
${ }^{3}$ Department of Biological Sciences, University of Southern California, University Park, Los Angeles, California 90007, USA
}

ABSTRACT: We have tested 136 specimens of soft corals (Coelenterata, Alcyonacea) for toxicity by exposing Gambusia affinis (Vertebrata, Pisces) to aqueous extracts of coral macerate and assessing mortality. Sixty-eight corals were examined in detail utilizing behavioral responses of fish as well as mortality rates to establish relative toxicities among and within coral genera. The responses exhibited by the fish ranged from rapid mortality through slow mortality and varying levels of narcotisation to negligible effects. With respect to individual soft corals, the fish exhibited varying patterns of response through time, and were sorted into 9 distinct groups via multivariate computer analyses according to similarity of these behavioral patterns. Only 2 of the genera tested, Lemnalia and Sarcophyton, were restricted to the most toxic set of groups. A number of genera such as Lobophytum, Sinularia, Nephthea, and Cespitularia had representatives which spanned the entire spectrum of responses from highly toxic to non-toxic. The wide range of toxicity determined for the specimens examined and the fact that approximately $50 \%$ of all specimens were toxic suggests that chemical defences against predation are common in the Alcyonacea of the central region of the Great Barrier Reef. Toxicity, however, occurs significantly less frequently in this group than in those examined from the northern Great Barrier Reef in an earlier study.

\section{INTRODUCTION}

Numerous marine organisms are known to contain toxins (Halstead, 1970, 1978; Rideout et al., 1979). Many soft corals (Coelenterata: Alcyonacea) possess an extensive range of unique organic molecules, the majority of which fall into the terpene class of compounds (Tursch et al., 1978; Coll et al., 1980; Coll, 1981). A number of these marine terpenoids have been shown to be distasteful (Lucas et al., 1979) or toxic (Ne'eman et al., 1974; Weinheimer et al., 1977). It has been suggested that these secondary metabolites may function as chemical defences against predation, fouling, and parasitism, conferring a selective advantage on some soft corals (Tursch et al., 1978).

A preliminary study of several soft corals from Lizard Island (northern region, Great Barrier Reef, Australia) indicated that most of those tested were toxic to fish (Bakus, 1981). In this paper we extend this survey to include a greater range of non-cryptic species to determine how widespread this toxicity is within the Alcyonacea and whether it is restricted to selected genera. We also attempt to establish a hierarchy of toxicity for the species of soft corals studied.

\section{MATERIALS AND METHODS \\ Collection of Specimens}

A large number of soft coral specimens (136) representing 15 genera common to the central region of the Great Barrier Reef, were collected from Britomart, Davies and Slashers Reefs as well as from Orpheus Island (Palm Island Group) $\left(18-19^{\circ} \mathrm{S}, 146^{\circ} 30^{\prime}-148^{\circ} \mathrm{E}\right)$. All collections were made between August and October, 1980. Specimens utilized in toxicity testing were placed in labeled plastic bags and deep frozen. 
Corresponding specimens were preserved in $70 \%$ ethanol and utilized as reference samples for taxonomic determinations. Identifications were made with the aid of Bayer $(1956,1961)$, Verseveldt (1977. 1980), and other references reviewed by TixierDurivault (1972).

\section{Toxicity Tests}

The general techniques utilized to determine toxicity were independently established by Yamanouchi (1955) and Bakus and Thun (1979). Toxicity tests were performed on all specimens as follows: $15 \mathrm{~g}$ of each specimen was excised, placed in freshwater $(30 \mathrm{ml})$ and macerated in a blender. The macerate was centrifuged at 10,000 RPM for $10 \mathrm{~min}$ and the supernatant decanted and divided into 3 equal portions. Two of these were used for immediate testing and the last for serial dilutions in the case of the most toxic coral extracts.

The organism used to determine toxicity was the common mosquito fish Gambusia affinis (Baird and Girard). This fish has been used successfully in previous toxicity studies (Cornman, 1968, Birkhead, 1972. Spiegelstein, 1973; Ne'eman et al, 1974), particularly in studies of the type performed here (Fernandez Bernaldo de Quiros, 1978).

Specimens were collected from a nearby creek approximately $24 \mathrm{~h}$ prior to testing and held in a large aquarium. The test aquarium consisted of a rectangular Perspex ${ }^{R}$ structure subdivided into 10 sets of 2 replicate compartments; each held a volume of approximately $400 \mathrm{ml}$. Divisions between the watertight compartments were translucent to help visually isolate specimens from each other. Three adult or subadult fish (100-300 $\mathrm{mg}$ in weight and 19-30 $\mathrm{mm}$ in standard length) were placed in each compartment in $200 \mathrm{ml}$ of freshwater. This number of specimens was the smallest which would yield some estimate of error variance per duplicate sample for each soft coral specimen. Different-sized fish were distributed uniformly among test containers. It was assumed that, in general, sexes of the 930 fish used were randomly distributed among test aquaria.

After 15 to 30 min, a portion of soft-coral extract was added to each compartment. Two replicate controls (containing fish and freshwater only) were utilized on conjunction with each test run of 5-9 soft coral extracts. The number of fish suffering mortality after 1.5, 12 and $24 \mathrm{~h}$ was recorded.

Sixty-eight of the above 136 specimens (representing all 15 genera) were tested in detail. The same general procedure was used as described above, but in this case, observations on the behavior of each fish were made more frequently and in greater detail:
(1) Location (surface, mid-water or bottom).

(2) Orientation (normal, lateral roll, vertical roll, or both lateral and vertical roll).

(3) Movement (none, hypoactive, normal, hyperactive).

(4) Fin activity (none, hypoactive, normal, hyperactive).

(5) Response to visual stimulus. A circular black object was moved rapidly toward the fish from above causing sudden shading (no response, hypoactive, normal, hyperactive).

(6) Mortality (alive or dead).

Behavioral patterns were recorded for each fish at $t_{0}$ (usually $10.00 \mathrm{~h}$ ) prior to the addition of extracts and after addition following a geometric time-scale: $22 \min , 45 \min , 1.5 \mathrm{~h}, 3 \mathrm{~h}, 6 \mathrm{~h}$ and $12 \mathrm{~h}$. Physical and chemical properties of the water in test aquaria were not monitored during the course of the study, as it was believed that any effective changes in these characteristics would become evident through the behaviour of control fish.

\section{Numerical Methods}

The behavioural data derived from fish subjected to soft-coral extracts were submitted to multivariate analysis by computer. They yielded a data-set consisting of $78 \times 6(468)$ 'test-occasions' (68 coral species plus 10 controls measured on 6 successive occasions). Each 'test-occasion', irrespective of treatment, was characterized by 6 observations on 6 fish, and each observation was regarded as a multistate nominal attribute (Williams and Lance, 1977) with a possible maximum of 4 states.

Theoretically, the appropriate strategy for classification of such a data-set would be the CENPERC model of Dale et al. (1971). As this has not yet been extended to cover nominal attributes with more than 2 states, a compromise solution was required. Here we allowed each pair of 'test-occasions' (for all possible pairs) to define a $2 \times 4$ contingency table for each observation, with the number of fish (from 6 ) in each state of observation representing the cell-entries. To explain further, let $x_{i j}$ be a cell entry, $I_{i}$ a row sum, $c_{j}$ a column sum, and $g$ the grand sum. The transmitted information $\Delta \mathrm{I}$ (Dale et al., 1970) may then be defined as

$$
\Delta \mathrm{I}=\mathrm{g} \ln \mathrm{g}-\sum_{I} r_{i} \ln r_{1}-\sum_{j} c_{j} \ln c_{j}+\sum_{l} \sum_{j} X_{j j} \ln x_{i j}
$$

(In our case, $r_{1}=r_{2}=6 ; g=12$.) We then sum the $6 \Delta \mathrm{I}$ values (one for each observation). The results $\Sigma \Delta I$ can be used as a distance measure, yielding the 'upper triangle of a $468 \times 468$ distance matrix.

The derived distance measures were then classified by the strategy variously known as Ward's (1963) 'error 
sum of squares' or Burr's (1970) 'incremental sum of squares' technique. The classification was truncated at the 7-group level, for below this, differences were too subtle to be clearly descriptive. In this way, groupings delineating 7 relatively discrete behavioral states were defined, each summarizing a set of responses.

The original data were then reanalyzed with respect to treatment (i.e. soft coral extract or control). Each of the 78 treatments and controls were associated with one of the possible 7 behavioral states for 6 successive sampling periods. The resultant sequences for each treatment were then converted into a set of 78 singlestep transition matrices (of order 7) (Bailey, 1974) and classified by the TRANMAT procedure (Dale et al., 1970). For reasons similar to those stated above, the classification was truncated at 9 toxicity groups, yielding a general hierarchy of toxicity by specimen. Each group comprised corals deemed most similar in relation to their passage through the 7 behavioral states with time (see 'Results').

\section{Serial Dilutions of Most Toxic Species}

Those specimens determined to be most toxic were retested to determine in greater detail the degree of their relative toxicity. The third portion of the aqueous soft-coral extract was diluted to $100 \mathrm{ml}$ with freshwater and thoroughly mixed. This afforded duplicate samples equivalent to $30 \%, 10 \%, 5 \%$ and $1 \%$ dilutions of the original extracts when made up to $200 \mathrm{ml}$ in freshwater. The same geometric time series as described above was used and mortality was recorded.

\section{Confirmation of Terpenoids in Solution}

In order to confirm the presence of terpenoid material in the aqueous extracts, the test solutions were extracted with diethylether. The residue obtained on removal of the solvent was then compared with the total organic extract of a freeze dried specimen of the coral in question, using thin layer chromatography on silica gel plates. Terpene residues appeared upon spraying the plates with vanillin in concentrated sulphuric acid. Coloured spots developed on warming of the sprayed plates (Coll et al., 1980).

\section{RESULTS}

The soft corals tested exhibited a wide range of toxicity (Table 1). Approximately one half of the 136 specimens were found to cause abnormal behaviour in Gambusia affinis; $15 \%$ were found to be highly toxic,
Table 1. Summary of preliminary results from toxicity tests on 136 specimens of soft corals. Specimens ranked from very toxic to non-toxic according to percent mortality of test fish exposed to soft-coral extracts. Under mortality heading, numerator represents number of fish dying; denominator represents number of fish tested per soft coral extract

\begin{tabular}{|c|c|c|c|c|c|}
\hline \multirow{2}{*}{$\begin{array}{l}\text { Toxicity } \\
\text { ranking }\end{array}$} & \multicolumn{3}{|c|}{ Mortality } & \multirow{2}{*}{ Description } & \multirow{2}{*}{$\begin{array}{c}\text { No. of } \\
\text { specimens } \\
\text { (percentages) }\end{array}$} \\
\hline & $90 \min$ & $12 \mathrm{~h}$ & $24 \mathrm{~h}$ & & \\
\hline 1 & $6 / 6$ & & & very toxic & $21(15)$ \\
\hline 2 & & $\geqslant 5 / 6$ & & toxic & $27(20)$ \\
\hline 3 & & & $\geqslant 4 / 6$ & harmful & $23(17)$ \\
\hline \multirow[t]{2}{*}{4} & & & $\leqslant 3 / 6$ & non-toxic & $65(48)$ \\
\hline & & & & total & 136 \\
\hline Controls & & & $\leqslant 3 / 6$ & non-toxic & $19(100)$ \\
\hline
\end{tabular}

killing all test organisms within $90 \mathrm{~min}$; $20 \%$ were somewhat less toxic although still noxious, killing $\geq 83 \%$ of the test fish within $12 \mathrm{~h} ; 17 \%$ required $12 \mathrm{~h}$ to kill $\geq 67 \%$ of the fish. These were considered 'harmful'. The remaining $48 \%$ were found to be nontoxic, i.e. the test fish did not exhibit behavioral patterns distinquishable from the controls. Confinement of the fish for $24 \mathrm{~h}$ induced high mortality and erratic behavior in all $G$. affinis. For this reason, data were only collected over the first $12 \mathrm{~h}$ of all subsequent experiments.

With respect to the 68 specimens examined in greater detail, the responses exhibited by the test fish were grouped by multivariate analysis into 7 distinct behavioral states (Table 2). These will herein be referred to as States $1-7$, ranging from the most abnormal to normal, respectively.

State 1 was characterized by all test fish dying; State 2 , by a $2 / 3$ mortality rate; in addition, the majority of fish were located at the surface of the test tank, exhibiting no activity and no response to visual stimulus. State 3 was similar to State 2 but only $1 / 3$ of the fish died, and the largest proportion of fish were found to be generally more active, although still hypoactive. In State 4 , only $1 / 4$ died, but most of the live fish were found on the bottom of the compartments on their sides, heavily narcotized, exhibiting no response to visual stimulus. In State 5 none of the fish died; the majority were capable of maintaining normal orientation, although heavily narcotized; there was no response to visual stimulation. State 6 varied subtly from the fifth state in that the fish's activity was generally depressed, but a strong response to visual stimulation was still recorded. State 7 was considered to comprise normal responses.

Based on similarity of sequences through the above states with time, individual coral species were sorted into 9 toxicity groupings (Table 3). The first 4 groups of 
Table 2. Gambusia affinis. Behavioral states in individuals exposed to crude extracts from various soft corals. Entries represent proportion of fish exhibiting a particular behavior. States determined from the collection of extensive behavioral data and analyzed by multivariate computer techniques (see text for methods)

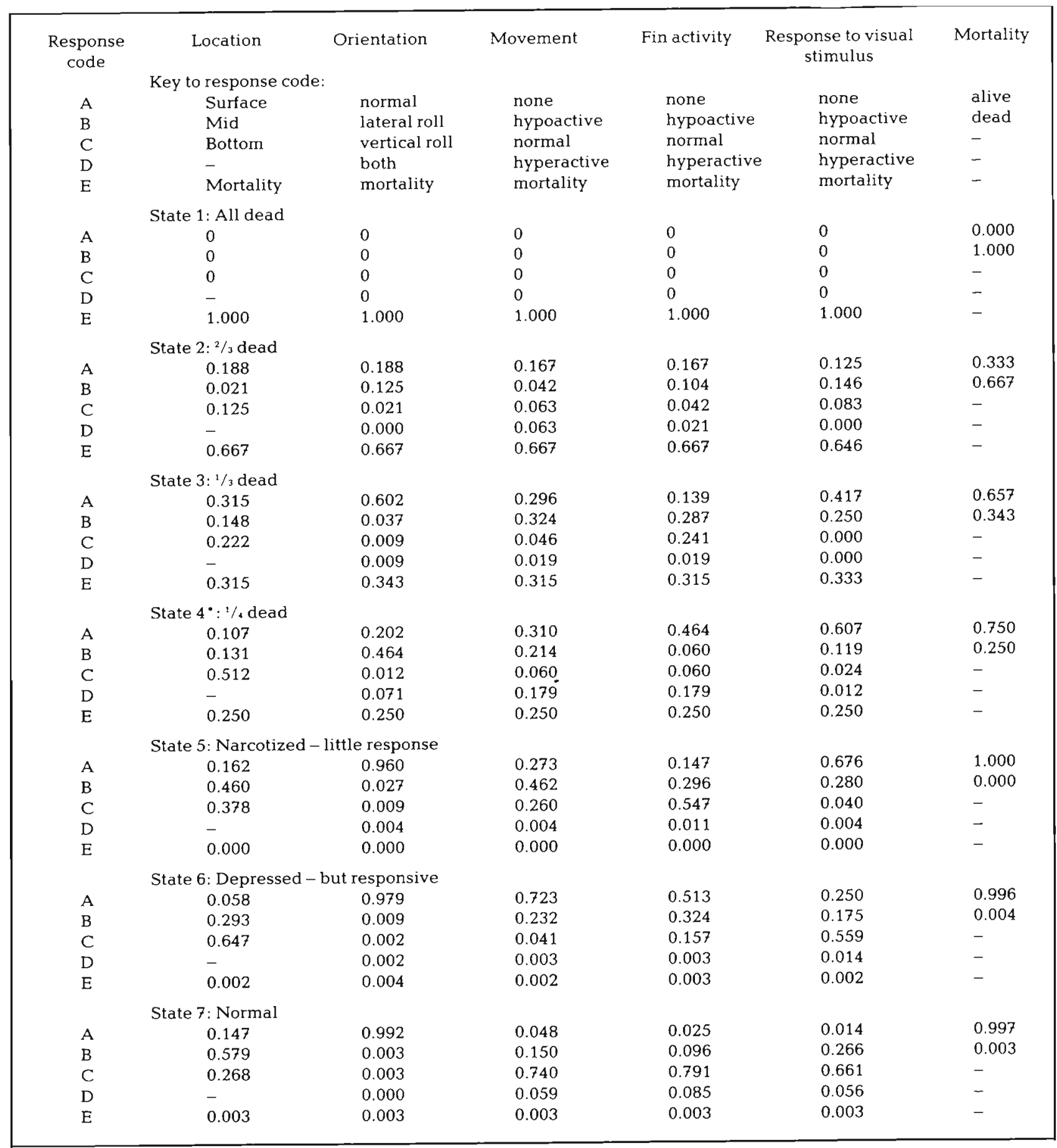

soft-coral species (I-IV) all yielded $100 \%$ mortality of the test organisms within $6 \mathrm{~h}$, but each of these groups varied in the development of abnormal symptoms and the actual amount of time required for mortality. The soft corals clearly delineated as toxic were Nephthea and Lemnalia (Family: Nephtheidae) and Sinularia,
Lobophytum, and Sarcophyton (Alcyoniidae). A Cespitularia (Xeniidae) was also found to be highly toxic. Even within each of these groups (I-IV), different species within a given genus induced varying results in terms of both behavioral states and time required for mortality. 
Table 3. Gambusia affinis. Behavioral responses through time during exposure to crude extracts of each of 68 soft corals. Each entry represents the responses of 6 fish as summarized by the behavioral states (1-7) defined in Table 2 (e.g. $1=$ all dead, $7=$ normal behaviour). Groups (I-IX) determined by multivariate computer analysis as described in text. Distinct but as yet unidentified species delineated by Sp. A, Sp. B, etc.

\begin{tabular}{|c|c|c|c|c|c|c|c|c|c|c|c|c|c|c|c|}
\hline \multirow[t]{2}{*}{ Genus } & \multirow[t]{2}{*}{$\begin{array}{l}\text { Specimen } \\
\text { number }\end{array}$} & \multicolumn{6}{|c|}{$\begin{array}{l}\text { Behavioral state } \\
\text { Time (min) }\end{array}$} & \multirow[t]{2}{*}{ Genus } & \multirow{2}{*}{$\begin{array}{l}\text { Specimen } \\
\text { number }\end{array}$} & \multicolumn{6}{|c|}{$\begin{array}{l}\text { Behavioral state } \\
\text { Time (min) }\end{array}$} \\
\hline & & 22 & 45 & 90 & 180 & & 720 & & & 22 & 45 & 90 & & & 720 \\
\hline \multicolumn{8}{|c|}{ Group I: 5 corals, all dead at $22 \mathrm{~min}$} & \multicolumn{8}{|c|}{ Group VII: 8 cor., 0 contr., narcotized - non responsive } \\
\hline Lemnalia sp. A & $\operatorname{TX} 13$ & 1 & 1 & 1 & 1 & 1 & 1 & Cespitularia sp. E & BT 8 & 5 & 5 & 5 & 5 & 6 & 6 \\
\hline Lobophytum sp. A & $\mathrm{BH} 40$ & 1 & 1 & 1 & 1 & 1 & 1 & Cladiella sp. A & $\mathrm{T} \times 27$ & 7 & 5 & 5 & 6 & 5 & 5 \\
\hline Nephthea sp. A & TX 15 & 1 & 1 & 1 & 1 & 1 & 1 & Dendronephthya sp. A & BT 14 & 5 & 5 & 6 & 6 & 6 & 6 \\
\hline Sarcophyton glaucum & $\mathrm{BH} 6$ & 1 & 1 & 1 & 1 & 1 & 1 & Nephthea sp. E & $\mathrm{BH} 45$ & 6 & 5 & 5 & 5 & 5 & 7 \\
\hline Sinularia flexibilis & $\mathrm{BH} 22$ & 1 & 1 & 1 & 1 & 1 & 1 & Nephthea striata & TX 14 & 5 & 5 & 5 & 6 & 5 & 5 \\
\hline \multirow{2}{*}{\multicolumn{8}{|c|}{ Group II: 4 corals, dying or dead at $45 \mathrm{~min}$}} & Parerythropodium sp. & $\mathrm{BH} 3$ & 5 & 5 & 5 & 5 & 5 & 6 \\
\hline & & & & & & & & Sinularia sp. H & $\mathrm{BH} 52$ & 5 & 5 & 5 & 5 & 5 & 5 \\
\hline Sarocophyton trocheliophorum & TX 18 & 4 & 1 & 1 & 1 & 1 & 1 & Sinularia sp. B & BT 18 & 5 & 5 & 5. & 5 & 6 & 3 \\
\hline Sinularia flexibilis & $\mathrm{BH} 8$ & 5 & 1 & 1 & 1 & 1 & 1 & & & & & & & & \\
\hline Sinularia sp.C & $\mathrm{BH} 17$ & 4 & 1 & 1 & 1 & 1 & 1 & \multicolumn{8}{|c|}{ Group VIII: 20 cor., 6 contr., mostly normal - depressed } \\
\hline \multirow[t]{2}{*}{ Sinularia sp. A } & BH54 & 4 & 1 & 1 & 1 & 1 & 1 & Control & Co 2 & 7 & 6 & 6 & 6 & 6 & 6 \\
\hline & & & & & & & & Control & Co 5 & 6 & 6 & 6 & 6 & 6 & 6 \\
\hline \multicolumn{8}{|c|}{ Group III: 9 corals, delayed response but very toxic } & Control & Co 6 & 6 & 6 & 6 & 6 & 6 & 6 \\
\hline Cespitularia sp. D & $\mathrm{BH} 41$ & 5 & 4 & 1 & 1 & 1 & 1 & Control & Co 7 & 7 & 6 & 6 & 6 & 6 & 6 \\
\hline Nephthea sp. B & BH59 & 5 & 5 & 2 & 1 & 1 & 1 & Control & Co 8 & 6 & 6 & 6 & 6 & 6 & 6 \\
\hline Sarcophyton digitatum & $\mathrm{BH} 11$ & 5 & 3 & 2 & 1 & 1 & 1 & Control & Co 10 & 6 & 7 & 6 & 6 & 6 & 6 \\
\hline Sarcophyton acutangulum (?) & $\mathrm{BH} 43$ & 5 & 4 & 1 & 1 & 1 & 1 & Anthelia sp. & $\operatorname{TX} 11$ & 7 & 6 & 6 & 6 & 6 & 6 \\
\hline Sarcophyton cherbomieri & DV 9 & 3 & 2 & 1 & 1 & 1 & 1 & Capnella sp. A & TX 9 & 6 & 6 & 6 & 6 & 6 & 6 \\
\hline Sinularia sp. D & $\mathrm{BH} 7$ & 5 & 5 & 4 & 1 & 1 & 1 & Capnella sp. C & BT 6 & 6 & 6 & 6 & 6 & 6 & 6 \\
\hline Sinularia flexibilis & $\mathrm{BH} 37$ & 5 & 5 & 3 & 1 & 1 & 1 & Capnella sp. B & $\mathrm{TX} 2$ & 6 & 6 & 6 & 6 & 5 & 5 \\
\hline Sinularia mollis & BT 4 & 5 & 5 & 3 & 1 & 1 & 1 & Cespitularia sp. C & BT 20 & 6 & 6 & 6 & 6 & 6 & 6 \\
\hline \multirow[t]{2}{*}{ Sinularia sp. E } & BT 10 & 5 & 5 & 3 & 3 & 1 & 1 & Cespitularia sp. A & TX 8 & 7 & 6 & 6 & 6 & 6 & 6 \\
\hline & & & & & & & & Cladiella sp. B & TX 10 & 6 & 6 & 6 & 6 & 6 & 6 \\
\hline \multicolumn{8}{|c|}{ Group IV: 2 corals, delayed effect but very toxic } & Dendronephthya sp. D & BT 3 & 6 & 6 & 6 & 6 & 6 & 6 \\
\hline Lemnalia sp. B & TX 52 & 4 & 4 & 4 & 1 & 1 & 1 & Dendronephthya sp.C & BT 11 & 6 & 6 & 6 & 6 & 6 & 6 \\
\hline \multirow[t]{2}{*}{ Lemnalia sp. B } & $\operatorname{TX} 63$ & 4 & 4 & 4 & 1 & 1 & 1 & Dendronephthyasp. A & BT $12 \mathrm{~A}$ & 6 & 6 & 6 & 6 & 6 & 6 \\
\hline & & & & & & & & Dendronephthya sp. A & BT 15 & 6 & 6 & 6 & 6 & 6 & 5 \\
\hline \multicolumn{8}{|c|}{ Group V: 9 corals, heterogeneous group - some toxic } & Dendronephthya sp.C & DV32 & 7 & 6 & 6 & 6 & 6 & 6 \\
\hline Lobophytum sp. B & $\mathrm{TX} 33$ & 7 & 7 & 5 & 7 & 5 & 3 & Lobophytum sp. C & DV12 & 6 & 6 & 6 & 6 & 5 & 6 \\
\hline Nephthea sp. G & TX 28 & 7 & 7 & 7 & 6 & 7 & 1 & Nephthea sp. E & $\mathrm{BH} 23$ & 7 & 6 & 6 & 6 & 6 & 6 \\
\hline Nephthea sp.C & $\operatorname{TX} 42$ & 7 & 5 & 7 & 4 & 2 & 1 & Nephthea sp. F & DV25 & 5 & 6 & 6 & 6 & 6 & 6 \\
\hline Sarcophyton sp. A & TX 3 & 7 & 7 & 7 & 7 & 2 & 1 & Scleronephthya sp. & $\mathrm{BH} 42$ & 6 & 6 & 6 & 5 & 6 & 6 \\
\hline Sarcophyton sp. B & $\operatorname{TX} 5$ & 7 & 5 & 5 & 5 & 5 & 2 & Sinularia sandensis & BT 1 & 6 & 6 & 6 & 6 & 6 & 6 \\
\hline Sinularia erecta & $\mathrm{BH} 5$ & 7 & 7 & 6 & 3 & 7 & 2 & Sinularia sp. I & $\mathrm{TX} 4$ & 6 & 6 & 6 & 6 & 6 & 6 \\
\hline Sinularia flexibilis & BT 9 & 7 & 5 & 6 & 6 & 5 & 2 & Sinularia sp. G & $\mathrm{BH} 13$ & 5 & 6 & 6 & 6 & 6 & 6 \\
\hline Sinularia sp. B & BT 16 & 5 & 5 & 6 & 5 & 3 & 1 & Xenia sp.C & $\mathrm{BH} 60$ & 7 & 6 & 6 & 5 & 6 & 6 \\
\hline Xenia sp. A & BT 7 & 6 & 5 & 6 & 6 & 3 & 1 & \multicolumn{8}{|c|}{ Group IX: 6 corals, 3 controls, normal } \\
\hline Group VI: 5 corals, 1 control, $n$ & harcotized, & dea & ath ir & sor & me $\mathrm{c}$ & cases & & Control & Co 1 & 7 & 7 & 7 & 7 & 7 & 6 \\
\hline Control & Co 4 & 6 & 6 & 6 & 6 & 6 & 4 & Control & Co 3 & 7 & 7 & 7 & 7 & 7 & 6 \\
\hline Cespitularia sp. B & $\mathrm{BH} 2$ & 6 & 6 & 6 & 3 & 3 & 3 & Control & Co 9 & 7 & 7 & 6 & 6 & 6 & 6 \\
\hline Dendronephthya sp. B & BT 13A & 6 & 6 & 6 & 6 & 6 & 3 & Alcyonium sp. & BH51 & 7 & 7 & 7 & 7 & 6 & 6 \\
\hline Nephthea sp. D & BT 2 & 6 & 6 & 6 & 6 & 5 & 3 & Cespitularia sp. F & TX 16 & 7 & 7 & 6 & 6 & 5 & 6 \\
\hline Sarcophyton globulosum & BT 17 & 6 & 6 & 6 & 6 & 5 & 3 & Efflatounaria sp. & $\mathrm{TX} 43$ & 7 & 7 & 7 & 6 & 5 & 6 \\
\hline Xenia sp. B & TX 1 & 7 & 6 & 6 & 6 & 5 & 3 & Nephthea striata & $\operatorname{TX} 17$ & 7 & 7 & 7 & 7 & 5 & 5 \\
\hline & & & & & & & & Paralemnalia sp. & TX38 & 7 & 7 & 7 & 7 & 7 & 7 \\
\hline & & & & & & & & Sinularia sp. F & $\operatorname{TX} 45$ & 7 & 7 & 7 & 7 & 7 & 7 \\
\hline
\end{tabular}

The second major set of soft-coral species groups (V-VII) was not generally characterized by $100 \%$ mortality but clearly induced severely abnormal behavior in the test organisms. Total fish mortality occurred occasionally and was caused only by 4 genera in Group V. Three of these were already found in the first major set of groups (I-IV) - Sarcophyton, Nephthea and Sinularia - the fourth was Xenia. Other soft corals in Group V which overlapped with Groups I-IV (e.g. Lobophytum and Sarcophyton) were somewhat less toxic. The species in Group VI were less lethal than those in Group V, inducing approximately $30 \%$ mor- 
Table 4. Summary of degree of toxicity by soft-coral genus and variability of toxicity within a genus. Table body: number of specimens falling into a particular toxicity group

\begin{tabular}{|c|c|c|c|c|c|c|c|c|c|c|}
\hline \multirow[t]{3}{*}{ Genera represented } & \multicolumn{9}{|c|}{ Toxicity groups } & \multirow{3}{*}{$\begin{array}{c}\text { No. of specimens } \\
\text { (species) }\end{array}$} \\
\hline & \multicolumn{4}{|c|}{$100 \%$ lethal } & \multicolumn{3}{|c|}{ Toxic } & \multicolumn{2}{|c|}{ Non-toxic } & \\
\hline & $\mathrm{I}$ & II & III & IV & V & VI & VII & VIII & $I X$ & \\
\hline Lemnalia & 1 & & & 2 & & & & & & $3(2)$ \\
\hline Sarcophyton & 1 & 1 & 3 & & 2 & 1 & & & & $8(8)$ \\
\hline Sinularia & 1 & 3 & 4 & & 3 & & 2 & 3 & 1 & $17(13)$ \\
\hline Nephthea & 1 & & 1 & & 2 & 1 & 2 & 2 & 1 & $10(8)$ \\
\hline Lobophytum & 1 & & & & 1 & & & 1 & & $3(3)$ \\
\hline Cespitularia & & & 1 & & & 1 & 1 & 2 & 1 & $6(6)$ \\
\hline Xenia & & & & & 1 & 1 & & 1 & & $3(3)$ \\
\hline Dendronephthya & & & & & & 1 & 1 & 5 & & $7(4)$ \\
\hline Control & & & & & & 1 & & 6 & 3 & $10^{(x)}$ \\
\hline Parerythropodium & & & & & & & 1 & & & 1 \\
\hline Capnella & & & & & & & & 3 & & $3(3)$ \\
\hline Anthelia & & & & & & & & 1 & & 1 \\
\hline Cladiella & & & & & & & & 1 & & 1 \\
\hline Scleronephthya & & & & & & & & 1 & & 1 \\
\hline Paralemnalia & & & & & & & & & 1 & 1 \\
\hline Efflatounaria & & & & & & & & & 1 & $\hat{1}$ \\
\hline Alcyonium & & & & & & & & & 1 & 1 \\
\hline
\end{tabular}

tality and requiring a longer period of time to produce symptoms of stress. The group again included representatives of previously occurring genera (Cespitularia, Nephthea, Sarcophyton and Xenia), but also Dendronephthya. Group VII was characterised predominantly by moderate narcotisation and negligible mortality. All genera occurring here were represented in other toxic groups, except Parerythropodium and Cladiella.

The third major set of species groupings (VIII and IX) were all characterised by, at worst, slightly depressed symptoms and negligible mortality. All these species were considered to be non-toxic and not significantly different from controls. Although many representatives of the above-mentioned genera fall into these groups, a number of less common genera were included:
Anthelia, Capnella, Paralemnalia, Efflatounaria, Scleronephthya, and Alcyonium.

The level of intraspecific variability of toxicity was not necessarily consistent from species to species. For example, while both specimens of Lemnalia sp. B fell clearly into Group IV, different colonies of Sinularia flexibilis were distributed among Groups I, II, III and $\mathrm{V}$. A summary of these data is presented in Table 4.

The dilution series experiments provided a ranking of the 9 most toxic species of soft corals (Groups I and II) to a greater degree of resolution (Table 5). Lemnalia (TX-13) was defined as the most toxic and Sinularia (BH-8) and Sarcophyton (TX-18) the least. The dilutions confirmed the distinction between Groups I and II.

Terpenes were confirmed to be present in the aque-

Table 5. Time required for serially diluted extracts of each of the 9 most toxic soft corals to induce mortality in Gambusia affinis. Table body: number of minutes for $100 \%$ mortality

\begin{tabular}{|c|c|c|c|c|c|c|}
\hline \multirow[t]{2}{*}{ Species name } & \multirow[t]{2}{*}{ Species number } & \multicolumn{5}{|c|}{ Dilutions } \\
\hline & & $100 \%$ & $30 \%$ & $10 \%$ & $5 \%$ & $1 \%$ \\
\hline Lemnaliasp. A & $\mathrm{TX} 13$ & 22 & 22 & $\cdot$ & $\cdot$ & $\cdot$ \\
\hline Nephthea sp. A & $\mathrm{TX} 15$ & 22 & 45 & $\cdot$ & $\cdot$ & $\cdot$ \\
\hline Sarcophyton glaucum & $\mathrm{BH} 6$ & 22 & 45 & $\cdot$ & • & $\cdot$ \\
\hline Lobophytum sp. A & $\mathrm{BH} 40$ & 22 & 90 & $\cdot$ & $\cdot$ & $\cdot$ \\
\hline Sinularia flexibilis & $\mathrm{BH} 22$ & 22 & 720 & $\cdot$ & $\cdot$ & $\cdot$ \\
\hline Sinulariasp. A & $\mathrm{BH} 54$ & 45 & 90 & 720 & $\cdot$ & $\cdot$ \\
\hline Sinulariasp. C & $\mathrm{BH} 17$ & 45 & 180 & $\cdot$ & $\cdot$ & - \\
\hline Sinularia flexibilis & $\mathrm{BH} 8$ & 45 & 360 & $\cdot$ & $\cdot$ & $\cdot$ \\
\hline Sarcophyton trocheliophorum & TX18 & 45 & 360 & $\cdot$ & $\cdot$ & $\cdot$ \\
\hline
\end{tabular}


ous test solutions of all toxic corals. Thin layer chromatograms of ether extracts of the test solutions were nearly identical with total extracts derived from the corals. No marked qualitative differences were observed between the two chromatograms.

\section{DISCUSSION}

In this study, we have determined the relative toxicity of 68 specimens of alcyonacean soft corals representing 15 genera. A major finding which emerges is that the soft corals examined induced a wide range of responses in test organisms, as has also been found for tropical sponges (Bakus and Thun, 1979). Responses ranged from death within a very short period of time (22 min) to almost no effects at all. Some corals caused only narcotizing effects; even these ranged from acute to mild. An intermediate group of corals appears to possess mildly toxic compounds which produce abnormal behavior in the test fish. These compounds do not interfere critically with essential life-supporting physiological processes on a short-term basis. It is possible that these sub-lethal effects may be due either to the pharmacological properties of these compounds or to the relative concentrations at which they are present in the coral tissue, neither of which is presently known for the corals tested in this study. In addition, it is uncertain whether any synergistic effects (positive or negative) resulted from the combination of confinement of test fish for $12 \mathrm{~h}$ and the presence of soft coral toxins.

The dilution studies demonstrated that even within the most toxic groups (I and II), toxicity varied and members of these groups could be ranked accordingly.

Of the corals tested, only 2 genera were restricted to the most toxic groups: Lemnalia and Sarcophyton. Representatives of a number of other genera Sinularia, Nephthea, Lobophytum, and Cespitulariainduced a wide variety of responses ranging from extremely toxic to non-toxic (indistinguishable from controls). A few other genera were found to be either mildly toxic or non-toxic. These included some of the less common and less diverse genera on the reef: Parerythropodium, Anthelia, and Cladiella.

The broad distribution of toxicity both among and within genera is clearly illustrated in Table 5; the trend from toxic to non-toxic is evident. In the preliminary survey using similar techniques, Xenia sp. was found to be toxic (Bakus, 1981). In our study, representatives of Xenia were found to range from moderately toxic to non-toxic and the closely related Cespitularia (Xeniidae) exhibited an even wider range of effects.

It is known from many examples in the terrestrial and marine environments that toxicity often functions as a non-energy requiring defense mechanism in prey
(Maiorana, 1979). This chemical defense has been favoured by natural selection in plants (e.g. Dawson et al., 1955; Whittaker and Feeny, 1971; Feeny, 1975; Selover and Crews, 1980) as well as in animals such as the monarch butterfly Danaus plexippus (Brower, 1969) and the crown-of-thorns starfish Acanthaster planci (Fish and Cobb, 1954; Halstead, 1974, 1978). It has been suggested that toxicity in non-cryptic sedentary or sessile marine invertebrates may have evolved via natural selection due to high intensities of fish predation (Bakus, 1969, 1975, 1976; Cameron and Endean, 1972; Cameron, 1974, 1976). Consistent with this hypothesis were the findings of Bakus' (1981) earlier study, demonstrating that 7 out of $8(88 \%$; $55.2-99.7 \%, 95 \%$ confidence limits; see Sokal and Rohlf, 1969) soft-coral specimens tested from the northern Great Barrier Reef were toxic. Our extension of that study to the central region of the Great Barrier Reef shows that 71 out of $136(52 \% ; 43.4-60.5 \%, 95 \%$ confidence limits) of the soft corals in this area are toxic. This is consistent with the belief that toxicity in general is common in tropical marine organisms (e.g. sponges, holothurians, etc.: Bakus, 1971, 1974; Bakus and Green, 1974; Green, 1977).

The wide variation in toxicity exhibited by species of some very common genera of soft corals suggests that toxicity represents one factor which contributes to the wide distribution of this group on the reef. In comparing our data directly with those of Bakus (1981) via Fisher's exact test (Sokal and Rohlf, 1969), however, we find that toxicity occurs significantly less frequently in soft corals from the central region versus the northern region of the Great Barrier Reef $(p<0.05)$.

Acknowledgements. We wish to thank the Australian Marine Sciences and Technologies Advisory Committee for financial support afforeded to J. C. Coll and S. La Barre, and the Australian Institute of Marine Science for logistic and other support. We also thank B. Bowden, D. McGuire, and D. Tapiolas for assistance in the field, D. McB. Williams for identification of the fish, and $\mathrm{H}$. J. Clay for carrying out extensive numerical analyses on the computer. All calculations were performed on the Cyber 76 computer in the C.S.I.R.O. Division of Computing Research, Canberra, A.C.T We thank C. R. C. Sheppard and P. Alderslade for valuable comments on the manuscript.

\section{LITERATURE CITED}

Bailey, N. T. J. (1964). The elements of stochastic processes, John Wiley and Sons, Inc, New York

Bakkus, G. J. (1969). Energetics and feeding in shallow marine waters. Int. Rev. gen. exp. Zool. 4: 275-369

Bakus, G. J. (1971). An ecological hypothesis for the evolution of toxicity in marine organisms. In: de Vries, A., Kochva, E. (eds.) Toxins of animal and plant origin. Gordon and Breach, New York, pp. 57-62 
Bakus, G. J. (1974). Toxicity in holothurians: a geographical pattern. Biotropica 6: 229-236

Bakus, G. J. (1975). Marine zonation and ecology of Cocos Island, off Central America. Atoll Res. Bull. 179: 1-12

Bakus, G. J. (1976). The biology and ecology of tropical holothurians. In: Jones, O. A., Endean, R. (eds.) Biology and geology of coral reefs, Vol. 2. Academic Press, New York, pp. 325-367

Bakus, G. J. (1981). Chemical defense mechanisms on the Great Barrier Reef, Australia. Science, N.Y. 211: 497-499

Bakus, G. J., Green, G. (1974). Toxicity in sponges and holothurians: a geographic pattern. Science, N.Y. 185: 951-953

Bakus, G. J., Thun, M. (1979). Bioassays on the toxicity of Caribbean sponges. Collog. Int. C.N.R.S. 291: 417-442

Bayer, F. M. (1956). Octocorallia. In: Moore, R. C. (ed.) Treatise on invertebrate paleontology, Part F, Coelenterata. Geol. Soc. Amer., Univ. of Kansas Press, Lawrence, pp. F166-F190

Bayer, F. M. (1961) The shallow water octocorallia of the West Indian region, Publ. Martinus Nijhoff, The Hague

Birkhead, W. S. (1972). Toxicity of stings of ariid and ictalurid catfishes. Copeia 1972(4): 790-807.

Brown, L. P. (1969). Ecological chemistry. Sci. Am. 220(2) $22-29$

Burr, E. J. (1970). Cluster sorting with mixed character types. II. Fusion strategies. Aust. Comput. J. 2: 98-103

Cameron, A. M. (1974). Toxicity phenomena in coral reef waters. Proc. second intl. coral reef symp., Vol. 1. Brisbane, Aust. pp. 513-518

Cameron, A. M. (1976). Toxicity of coral reef fishes. In: Jones, O. A., Endean, R. (eds.) Biology and geology of coral reefs, Vol. 3. Academic Press, New York, pp. 155-176

Cameron, A. M., Endean, R. (1972). The venom glands of teleost fishes. Toxicon 10: 301-303

Coll, J. C. (1981). Soft coral research at the James Cook University of North Queensland. Proc. Fourth Asian Symp. Medicinal Plants and Spices, Bangkok. UNESCO Spec. Publ. 1981, pp. 197-204

Coll, J. C., Bowden, B. F., Mitchell, S. J. (1980). Marine natural products chemistry at the James Cook University of North Queensland. Chem. Aust. 47: 259-263

Cornman, I. (1968). Dregs from the sea: Heterotargeting. In: Freudenthal, H. D. (ed.) Drugs from the sea. Trans. Symp., Univ. Rhode Island, Aug. 1967. J. Ocean Technol. of Mar. Technol. Soc. 1968: 117-183

Dale, M. B., Lance, G. N., Albrecht, L. (1971). Extensions of information analysis. Aust. Comput. J. 3: 29-34

Dale, M. B., MacNaughton-Smith, P., Williams, W. T., Lance, G. N. (1970). Numerical classification of sequences. Aust. Comput. J. 2: 9-13

Dawson, E. Y., Aleem, A. A., Halstead, B. W (1955). Marine algae from Palmyra Island with special reference to the feeding habits and toxicology of reef fishes. Occ. Pap. Allan Hancock Fdn 17: 1-39

Feeny, P. P. (1975). Biochemical evolution between plants and their insect herbivores. In: Gilbert, L. E., Raven, P. H. (eds.) Coevolution of animals and plants. Univ. of Texas Press, Austin, pp. 3-19

Fernandez Bernaldo de Quiros, C. (1978). Toxicity of techni- cal Coumachlor and of Tomorin on Gambusia affinis. Boln R. Soc. esp. Hist. nat. (Secc. Biol.) 76 (1/2): 109-122

Fish, C. J., Cobb, M. C. (1954). Noxious marine animals of the central and western Pacific Ocean. U.S. Fish Wildlife Service, Res. Rept. 36: 21-23

Green, G. (1977). Ecology of toxicity in marine sponges. Mar. Biol. 40: 207-215

Halstead, B. W. (1970). Poisonous and venomous marine animals of the world, Vol. 3, U.S. Govt. Printing Office, Washington, D.C.

Halstead, B. W. (1974). Marine biotoxicology. In: Coulston, F., Korte, F. (eds.) Environmental quality and safety, Vol. 3. Academic Press, New York, pp. 212-239

Halstead, B. W. (1978). Poisonous and venomous marine animals of the world, Darwin Press, Inc., Princeton, N.J.

Lucas, J. S., Hart, R. J., Howden, M. E., Salathe, R. (1979). Saponins in eggs and larvae of Acanthaster planci (L.) (Asteroidea) as chemical defenses against planktivorous fish. J. exp. mar. Biol. Ecol. 40 (2): 155-165

Maiorana, V. C. (1979). Nontoxic toxins: the energetics of coevolution. Biol. J. Linn. Soc. 11 (4): 387-396

Ne'eman, I., Fishelson, L., Kashman, Y. (1974). Sarcophine A new toxin from the soft coral Sarcophyton glaucum (Alcyonaria). Toxicon 12: 593-598

Rideout, J. A., Smith, N. B., Sutherland, M. D. (1979). Chemical defense of crinoids by polyketide sulphates. Experientia 35 (10): $1273-1274$

Selover, S. C. J., Crews, P. (1980). Kylinone, a new sesquiterpene skeleton from the marine alga Laurencia pacifica. J. org. Chem. 45 (1): $69-72$

Sokal, R. R., Rohlf, F. J. (1969). Biometry, W. H. Freeman and Co., San Francisco

Spiegelstein, M. Y. (1973). Purification and biological activity of Gymnodinium breve toxins. Toxicon 11 (1): 85-93

Tixier-Durivault, A. (1972). Nouvel apport d'octocoralliaires. Tethys, 3 (Suppl.): 66-68

Tursch, B., Braekman, J. C., Daloze, D., Kaisin, M. (1978). Terpenoids from coelenterates. In: Scheuer, P. J. (ed.) Marine natural products, chernical and biological perspectives, Vol. II. Academic Press, New York, pp. 247-296

Verseveldt, J. (1977). Australian octocorallia (Coelenterata). Aust. J. mar. Freshwater Res. 28: 171-240

Verseveldt, J. (1980). A revision of the genus Sinularia May (Octocorallia: Alyonacea). Zoologische Verhandelingen 179: $1-166$

Ward, J. H. (1963). Hierarchical grouping to optimize an objective function. J. Am. statist. Ass. 58: 236-244

Weinheimer, A. J., Matson, J. A., Bilaget Hossain, M., Van der Helm, D. (1977). Marine anticancer agents Sinularin and Dihydrosinularin. New cembranolides from the soft coral Sinularia flexibilis. Tetrahedron Lett. 34: 2923-2926

Whittaker, R. H., Feeny, P. P. (1971). Allelochemics: Chemical interactions between species. Science, N.Y. 171 (3973): $757-770$

Williams, W. T., Lance, G. N. (1977). Hierarchical classificatory methods. In: Euslein, K., Ralston, A., Wilf, H. S. (eds.) Statistical methods for digital computers. Wiley, London, pp. 269-295

Yamanouchi, T. (1955). On the poisonous substance contained in holothurians. Publs Seto mar. biol. Lab. 4: 183-203 